\title{
A skin-picking disorder case report: a psychopathological explanation
}

Um caso clínico sobre skin-picking disorder:

uma explicação psicopatológica

Ângela Ribeiro', João Pedro Ribeiro', Orlando von Doellinger

\section{ABSTRACT}

\section{Keywords}

Self-injurious behavior, self-mutilation, psychopathology.

We describe the case of a 44-year-old woman, without known previous psychiatric history, hospitalized after a significant hemorrhage caused by self-inflicted deep facial dermal lesions (with muscle exposition). Psychopathological possible explanations of this case, as in similar reviewed ones, are related to frustration, aggression, and impulsivity.

\section{RESUMO}

\section{Palavras-chave}

Comportamento

Descrevemos um caso clínico de uma senhora de 44 anos de idade, sem antecedentes psiautomutilatório, automutilação, psicopatologia. quiátricos prévios, internada após hemorragia significante causada por uma lesão facial autoinfligida (com exposição de músculo). Possíveis explicações psicopatológicas deste caso, tal como em casos similares, relacionam-se com frustração, agressividade e impulsividade. 


\section{INTRODUCTION}

Skin picking disorder (SPD) is characterized by repetitive and compulsive picking of skin, leading to tissue damage. It is also known as pathological skin picking, dermatillomania, psychogenic excoriation, or "neurotic excoriation" (as firstly described by Erasmus Wilson, in 1875, in neurotic patients with excessive picking behaviours)'.

Although documented in medical literature since the $19^{\text {th }}$ century, only recently changed from being considered a residual diagnosis related to impulse control to a listed diagnosis in the range of the obsessive-compulsive disorders.

SPD is often a diagnosis of exclusion, and the differential diagnosis of self-inflicted skin lesions can be separated between purely medical aetiologies, purely psychiatric aetiologies and a combination of both².

More than a decade of growing literature on SPD's prevalence in the community points its rates ranging from $1.2 \%$ to $5.4 \%$ in various cohorts ${ }^{3}$. The most commonly picked body parts are the face, arms, and legs ${ }^{3}$, and individuals may pick at healthy skin, but also at minor skin irregularities. Most of them often spend significant time on repetitive picking (sometimes for several hours at a time) with an inability to stop despite ongoing skin damage 4 .

Patients with SPD often resort to a general practitioner or to a dermatologist before consulting a psychiatrist, while most never appeal to an initial psychiatric consultation. The clinical impact of the disorder should not be underestimated, for its substantial functional impairment, as patients with SPD experience different psychosocial difficulties including anxiety, social embarrassment, avoidance and loss of productivity at work ${ }^{5}$. Possible medical sequelae include infections, lesions, scarring, and serious physical disfigurement ${ }^{6}$. In severe cases, individuals may be at heightened risk of mortality and in need of neurosurgical intervention?.

Psychiatric comorbidity comprise different disorders such as depression, anxiety, substance abuse, mood disorders, OCD and trichotillomania ${ }^{2,8}$.

Clinical evaluation of patients with SPD demands a broad physical and psychiatric examination, leading to an interdisciplinary approach to evaluation and treatment ${ }^{1}$.

Reports of nonpharmacologic treatments include acceptance-enhanced behaviour therapy, internet-based support groups, engaging in competitive activities, habit reversal, cognitive behavioural therapy, and contingent glove wearing $^{8}$.

Despite the significant clinical impact of skin picking disorder, no clear pharmacological therapeutic guidelines are available for now. Some reports found selective serotonin reuptake inhibitors (SSRIs) effective in pathologic skin picking ${ }^{9}$, with improvement in picking behaviour and reduction of the lesions, with other reports providing conflicting results $^{10}$. Some studies have demonstrated the efficacy of anti- epileptic drugs in skin picking disorder ${ }^{11}$ and suggested that the association between antidepressants and antiepileptic drugs might be beneficial in some impulse control disorders $^{12}$. Augmentation strategies have been shown effective with haloperidol/fluvoxamine as well as combined with psychotherapy ${ }^{13}$.

Further research, both in the clinical and the neurobiological fields, is needed to clarify the usefulness of pharmacotherapy.

\section{CASE REPORT}

F, a 44-year-old married woman, with two children (a 25year-old boy and 24-year-old girl), had no personal or familiar psychiatric background when referred to our hospital's emergency department, with a significant facial haemorrhage. After surgical assessment and orientation, realizing the self-inflicted nature of a right mandibular deep skin lesion, she was transferred for psychiatric evaluation.

Diagnosed with fibromyalgia a few years ago, she was prescribed with paracetamol and alprazolam $(0.25 \mathrm{mg}$ per day) for the last 4-5 years. She denied any other substances consumption.

The patient reported the beginning of the self-inflicted behaviour over the last six months, after checking her face for a bump with a cyst-like lesion, non-superficial, and started to gradually picking it. She admitted having a private consultation with a dermatologist, after which she was prescribed with local antibiotics and a plastic and reconstructive surgery referral (which she did not attend). In the absence of improvements, according to the patient, she began "trying to end it by [her] means"; she began picking the lesion, firstly, with her fingernails, but quickly resorting to needles and cotton swabs (which she used to perform a self-non-medicallysupervised-drainage of "the dirtiness") to stop minor (and later bigger) bleedings. These behaviours became repetitive, compulsive and persistent, while voluntary hidden from her family for the most possible time. A psychiatric admission was prompted and accepted by the patient on (her) perspective of faster medical support for her "lesion". During her short hospital admission, organic etiology assessment included laboratory tests (complete blood cell counts, electrolytes, liver and renal functions, TSH, blood fat level), ECG and head CTs, all within limits and with no acute brain lesion). An assessment on the patient's personality was made, which revealed predominantly obsessive (specially preoccupation with orderliness and perfectionism) and depressive traits. No criteria for a major depressive disorder or obsessive-compulsive disorder specific diagnosis were met.

Complete personal and familiar backgrounds were brought to our knowledge. In brief, F. is the second of four children, and always felt being neglected and not (enough) 
loved by her parents. She described a long dysfunctional marital relationship with an aggressive and undervaluing husband with an alcohol addiction that resulted in periods of "depressiveness" and suicidal thoughts when major conflicts arose. She added a deep feeling of sadness in relation to her son's life (living abroad for seven years), but with whom she described a "very close" relationship. Recently, her mother died after a long hospitalisation, event that she says was "a relief" as she visited her mother everyday at the hospital ("and I have fibromyalgia, you know; I'm always in pain", she added).

Throughout her own psychiatric hospitalization period, a prescription of fluvoxamine $75 \mathrm{mg} /$ day was titrated along with alprazolam $2 \mathrm{mg}$ /day. General surgery and dermatology's assessments were repeated. She presented no complaints, other than the facial "lesion". Her posture was somewhat immature, rapidly gaining (superficial) affection for other inpatients. No other significant changes at the mental status examination were shown. An outpatient consultation was, then, scheduled.

During the first consultations, the patient seemed to show some improvements, not repeating the self-inflicted injuries. However, three months after her psychiatric admission, she revealed getting back to the same behavioural pattern with repetitive and compulsive urges to pick at the scarred facial tissues. An anti-psychotic was, then, initiated (haloperidol, $2 \mathrm{mg} /$ day) and combined with an increased dose of the same SSRI (100 mg/day). Behavioural improvements were noticed, with no known skin picking episodes over the last five months, and the patient has become more self aware of its significance.

\section{DISCUSSION}

Psychopathological explanations of clinically relevant cases of self-injury behaviours (SIB) include psychodynamic, cognitive and neurochemical models. Frustration, aggression, and impulsivity appearing in helpless situations appear to be a common script across all these models. The inherent needs, sexual or aggressive, may not have safe ways for expression. These, together with the blocking of (desired) needs in the social context (and/or in fantasy), may trigger various forms of SIB based on these psychological states ${ }^{14}$.

Some of the psychiatric disorders and social stressors may be well hidden because of shame or a delusional belief system. Psychodynamic issues may focus on suppression or on repression of aggression relating to unmet emotional needs. These may arise from past or current situations and be difficult to resolve directly ${ }^{2}$. It has been also postulated that SIB may be used to express emotion and conflict to others (and to the self). Whether as a mean to achieve a sense of self control to an overwhelming threatening emotion, or as one to regulate affect through distancing (dissociation) ${ }^{15}$.
Some traits associated to these patients include: low selfconfidence, generalized apprehension, meticulousness and depressive mood and hypersensitivity to perceived negativism toward themselves ${ }^{2}$.

In F. it seems that the death of her mother aggravated previous behaviours of self-harm. A child who felt neglected and not loved by her parents, a woman who married an abusive man, a mother who feels the "loss" of her son (her only loved and loving one), F. is always seeking for affection but, at the same time, feeling that she is not good enough to deserve it. The death of her mother, one more abandonment and rejection, of which she talked in a dissociative manner, may have triggered a more profound self-depreciative sense of herself and a major aggressive drive that she turned into herself (not only because it was safer, but because she introjected de lost and rejecting objects).

\section{CONCLUSIONS}

In this case report we describe a female patient who picks at her face on a daily basis, causing a self-inflicted right mandibular deep skin lesion. It was associated with emotional stress followed by a feeling of relief after picking. She meets the proposed diagnostic criteria for SPD.

This patient did not have any associated psychiatric comorbidity; however, important findings that deserve attention are the prominence of personality obsessive traits, coexistent periods of "depressiveness" and suicidal thoughts associated with a dysfunctional marital relationship.

Our psychotherapeutic approaches have primarily focused on safer means of expression of possible underlying individual conflicts, as well as developmental issues, which altogether may play an important role on the patient's understanding of her symptoms.

Although initial behavioural improvements may be accounted for the antidepressant, skin picking behaviours were better sustainably reduced when treatment included antipsychotic which might point out to the referred benefits of combined therapies and augmentation strategies ${ }^{3}$.

\section{INDIVIDUAL CONTRIBUTIONS}

Ângela Ribeiro - Has substantially contributed to conception, interpretation and drafting of this case report as well as its literature review.

João Pedro Ribeiro and Orlando von Doellinger Have substantially contributed to drafting and critically revising this manuscript.

All authors were part of the team responsible for the patient's care and have directly contributed to conception and interpretation of this case report, substantially contributed to drafting and critically revising this manuscript and have given the final approval of the version to be published. 


\section{CONFLICTS OF INTEREST}

The authors report no proprietary or commercial interest in any product mentioned or concept discussed in this article.

\section{REFERENCES}

1. Grant JE, Odlaug BL, Chamberlain SR, Keuthen NJ, Lochner C, Stein DJ. Skin picking disorder. Am J Psychiatry. 2012;169(11):1143-9.

2. Peggy RC, George KD. Neurotic excoriations. Am Fam Physician. 2001;64(12):1981-5.

3. Odlaug BL, Grant JE. Pathologic skin picking. In: Grant JE, Stein DJ, Woods DW, Keuthen NJ, editors. Trichotillomania, skin picking and other body-focused repetitive behaviors. Washington, DC: American Psychiatric Publishing, Inc; 2012. p. 21-41.

4. Grant JE, Odlaug BL, Hampshire A, Schreiber L, Chamberlain SR. White matter abnormalities in skin picking disorder: a diffusion tensor imaging study. Neuropsychopharmacol. 2013;38(5):763-9.

5. Tucker BT, Woods DW, Flessner CA, Franklin SA, Franklin ME. The skin Picking Impact Project: phenomenology, interference, and treatment utilization of pathological skin picking in a population-based sample. J Anxiety Disord. 2011;25(1):88-95.
6. Odlaug BL, Grant JE. Clinical characteristics and medical complications of pathologic skin picking. Gen Hosp Psychiatry. 2008;30(1):61-6.

7. Kondziolka D, Hudak R. Management of obsessive-compulsive disorder-related skin picking with gamma knife radiosurgical anterior capsulotomies: a case report. J Clin Psychiatry. 2008:69(8):1337-40.

8. Spiegel DR, Finklea $\mathrm{L}$. The recognition and treatment of pathological skin picking: a potential neurobiological underpinning of the efficacy of pharmacotherapy in impulse control disorders. Psychiatry (Edgmont). 2009;6(2):38-42.

9. Bloch M, Elliott M, Thompson H, Koran L. Fluoxetine in pathologic skin-picking: open-label and double-blind results. Psychosomatics. 2001;42(4):314-9.

10. Denys $D$, van Megen HJ, Westenberg HG. Emerging skin picking behaviour after serotonin reuptake inhibitor-treatment in patients with obsessive compulsive disorder: possible mechanisms and implications for clinical care. J Psychopharmacol. 2003;17(1):127-9.

11. Grant JE, Odlaug BL, Kim SW. Lamotrigine treatment of pathologic skin picking: an openlabel study. J Clin Psychiatry. 2007;68(9):1384-91.

12. Schupak C. Case report: lamotrigine/fluoxetine combination in the treatment of compulsive sexual behaviour. Prog Neuropsychopharmacol Biol Psychiatry. 2007;31(6):1337-8.

13. Turner GA, Sutton S, Sharma A. Augmentation of venlafaxine with aripiprazole in a case of treatment-resistant excoriation disorder. Innov Clin Neurosci. 2014;11(1-2):29-31.

14. Rao NK, Sudarshan CY, Begum, S. Self-injurious behavior: a clinical appraisal. Indian J Psychiatry. 2008;50(4):288-97.

15. Karen L, Suyemoto. The functions of self-mutilation. Clin Psychol Rev. 1998;18(5):531-54. 